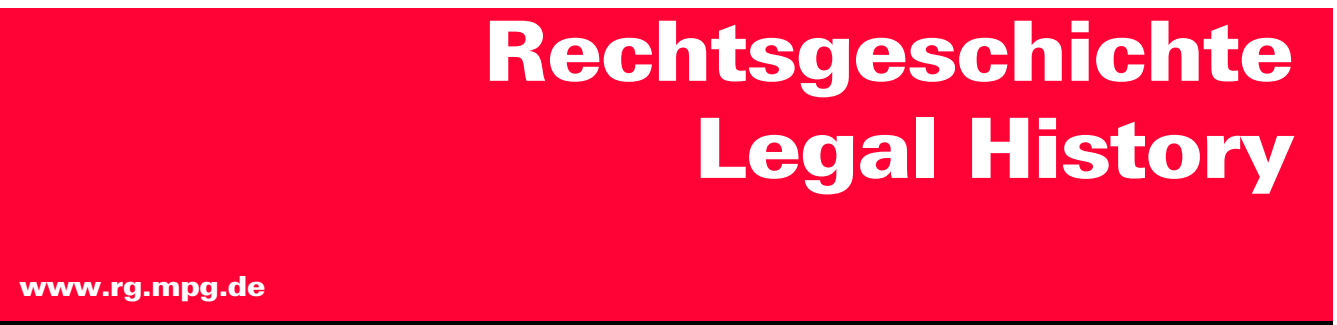

http://www.rg-rechtsgeschichte.de/rg27

$\operatorname{Rg} 272019 \quad 390-392$

Zitiervorschlag: Rechtsgeschichte - Legal History Rg 27 (2019)

http://dx.doi.org/10.12946/rg27/390-392

\title{
Carlos Petit*
}

\section{Luces y sombras sobre la Sombra de Vitoria}

[The Lighter and Darker Side of Assessing Vitoria's Shadow]

\footnotetext{
* Universidad de Huelva, cpetitcalvo@gmail.com
}

Dieser Beitrag steht unter einer Creative Commons Attribution 4.0 International License 


\section{Carlos Petit \\ Luces y sombras sobre la Sombra de Vitoria*}

La expresión Derecho Internacional tiene dos principales sentidos. Por un lado, se trata del ámbito de reglas, usos y convenciones que disciplinan las relaciones entre estados y sus asociaciones, con el objetivo confesado de evitar la confrontación bélica. Por otro lado, llamamos Derecho Internacional al estudio que, sobre todo lo anterior, elaboran los juristas expertos en este sector técnico. Sustancia jurídica y tradición científica, en suma.

Ignacio de la Rasilla se centra en esa tradición (»the historical evolution of the study of international law«, 19), esto es, en la ius-internacionalística española, pero dedica varios capítulos a la sustanciar. Al autor le interesan los efectos que ciertos turning points de la historia de España tuvieron sobre las teorías y enseñanzas de los juristas; grandes acontecimientos de nuestro pasado (la guerra de Cuba, los >desastres en Marruecos, la maldita guerra civil) que enmarcaron el quehacer, las carreras profesionales, los textos (de la ciencia) del Derecho Internacional, de modo que los excursos históricos ofrecen el contexto factual que dio sentido a las prácticas de los internacionalistas. Y en esos capítulos de scontexto (los caps. 2, 3 y 4) se encuentra, en mi opinión, lo mejor de la obra.

Entre la sustancia internacional y las doctrinas jurídicas In the Shadow of Vitoria encuentra un hilo conductor - a la postre, algo débil - en la fortuna intelectual del profesor de Sagrada Teología Francisco de Arcaya (1483/86-1546), más conocido como Francisco de Vitoria. La recuperación del fraile dominico como founding father de la disciplina nació - falsa paradoja - de la celebración en 1883 del tercer centenario de Hugo Grocio (80 ss.), cuando una corta mas influyente cohorte de autoridades extranjeras (James Lorimer, Ernest Nys, Alphonse Rivier) descubrieron a los españoles (Manuel Torres Campos, Eduardo de Hinojosa, Marcelino Menéndez Pelayo), en la estela del Neotomismo de León XIII (Aeterni Patris, 1879), las excelencias de la Escuela de Salamanca. Vitoria fue también la prueba del nueve de la calidad de la dominación hispana sobre las Indias - integradora, humanitaria, apostólica - en comparación con la inglesa, guiada por una finalidad egoísta. Por eso, el consenso sobre la paternidad del Derecho Internacional en Vitoria, generalizado en la Europa siusnaturalistar de entreguerras, fue el antecedente cronológico y textual del nuevo renacimiento sfascistar de la Segunda Escolástica bajo el franquismo (268 ss.).

Más allá de los aciertos indudables en la narración de los >descubrimientos< sucesivos del teólogo dominico - »Vitoria’s reputation«, escribió Carl Schmitt y repite De la Rasilla, »has its own history and requires special treatment « (1); me temo que aún sigue así - la descripción de los contextos históricos de la ciencia española del Derecho Internacional contiene lo mejor de la obra. Ha sido un acierto el capítulo segundo (»A Point of Inflection for International Law in Spain and the United States", 89-153) centrado en la llamada guerra de Cuba, pues aquel conflicto hispano-norteamericano tuvo un impacto doctrinal concreto en los dos países afectados. Desde luego los Estados Unidos acompañaron finalmente su universalismo comercial - tan evidente en los tratados desigualitarios impuestos a los imperios asiáticos - con la creación de instituciones y la formación de expertos en la materia jurídicointernacional (case-book de Freeman Snow, 1893, 101; American Society of International Law, 1906, 139 ss.; apoyo financiero de Andrew Carnegie al movimiento de la paz y el arbitraje; American Journal of International Law, 1907). La pujante nación americana se asimiló además a las potencias europeas tras adquirir, a expensas de la declinante España, varios dominios coloniales (192 ss. sobre »The Insular Cases«).

En ese otro país los años 1880 conocieron una reforma de los estudios jurídicos que estableció el

\footnotetext{
* Ignacio de la Rasilla del Moral,

In the Shadow of Vitoria: A History

of International Law in Spain

(1770-1953), Leiden / Boston:

Brill Nijhoff 2018, xvi + 353 p.,

ISBN 978-90-04-34322-1
} 
Derecho Internacional como materia de enseñanza obligatoria. Fue entonces cuando comenzó su actividad de estudioso y bibliógrafo el prestigioso Ramón Dalmau, marqués de Olivart (76ss.), y pronto se sumaron la docencia del krausista Aniceto Sela en Oviedo, las tesis de doctorado de argumento internacional, la creación, en fin, de revistas (Revista de Derecho Internacional, Legislación y Jurisprudencia Comparadas, 1887; Revista de Derecho Internacional y Política Exterior, 1905). La crisis antillana y filipina consumó además el giro africanista de España (133 ss., »Colonial Policy of Substitution«), cuando las grandes conferencias de la Paz y la actividad incesante de James Brown Scott (»The Omnipresent Amigo Americano«, 149 ss.) lanzaron convenciones y textos (los »Classics of International Law«, 44 vols. entre 1911 y 1940, con notable presencia de la Escuela de Salamanca) que permitieron dar un paso de gigante a los cultivadores del Derecho Internacional.

Merece asimismo todo aprecio el capítulo cuarto, dedicado a la guerra civil. En realidad, a la luz de sus páginas (»The Spanish Civil War. Inter Armas Pugnant Leges«, 224-267), el terrible acontecimiento se nos presenta como una cruenta guerra internacional y desigual librada contra la República española por la parte insurrecta del ejército y el rendido apoyo de Alemania e Italia ... con la neutralidad culpable impuesta por Gran Bretaña. La contribución inglesa a favor de los rebeldes (»better Franco than Stalin«, según el chargé d'affaires Georges Ogilvie-Forbes) desde la política de snon-intervention< se diseña en este libro con meridiana claridad. Interesado siempre en las doctrinas, Rasilla procede además al análisis de los esfuerzos teóricos - sobre todo Arnold McNeir (240ss.), pero también Hersch Lauterpacht (247 ss.) - desplegados para apuntalar la imposible legalidad de la posición británica.

El interés de ambos capítulos no impide pronunciar un juicio más severo sobre la descripción del Derecho Internacional en el segundo sentido identificado más arriba, esto es, como la especialidad académica que Rasilla pretende mostrarnos según un »bio-academic excursus of certain figures« (19). Por una parte, la corta atención dispensada a la España ilustrada y gaditana (28 ss.) apenas un censo de los materiales y nombres más obvios, no exento de dislates ${ }^{\mathbf{1}}$ - conspira contra el término a quo de su investigación; existe una nutrida literatura sobre las reformas de Carlos III y la condición >bihemisférica de la Constitución de 1812 que no debería desconocerse tan alegremente. ${ }^{2}$ Por otra parte, merece la misma objeción la poca atención prestada a los planes de estudio de la España liberal y las trayectorias de los internacionalistas que los aplicaron: contamos con instrumentos suficientes para comprender las llamadas stesis doctorales (54 ss.; se trataba de discursos ceremoniales de argumento fijado cada año por la facultad de Madrid), apreciar las novedades decisivas de las reformas de 1883-1884; en fin, para reconstruir las carreras de los juristas que ocuparon (desde 1842, nada menos) las cátedras dedicadas a la docencia del Derecho Internacional. ${ }^{3}$

No cabe duda que el autor conoce su objeto y que estaba capacitado para componer una obra de lectura sugestiva - no obstante la repetición superflua de datos y argumentos. ${ }^{4}$ Pero tampoco cabe
1 Sobre "the deposition of the Spanish monarch by Napoleon's brother" se nos habla en 39. Tampoco parece feliz destacar la naturaleza »democratically advanced « de la Constitución de 1812 (43), la condición "moderada « de la de 1837 (46; ese adjetivo, de valor histórico, corresponde mejor al texto constitucional de 1845), ni considerar la Revista General de Legislación y Jurisprudencia (1853) como »the first professional law journal published in the Spanish language«: esa primacía corresponde al Boletín de Jurisprudencia y Legislación (1836), donde hubiera sido de interés consultar MANUEL Pérez Hernández, »Del Derecho natural«, ibid. 2 (1836) 57-64.
2 Por limitarme a lo último, vid. Fernando Liendo Tagle, Pablo de Olavide y la nueva planta de los estudios, Madrid 2016, 97 ss., 151 ss. sobre el Derecho Natural y de Gentes, »origen y fuente de todas las Leyes«. Sobre Cádiz, José María Portillo, Revolución de nación: orígenes de la cultura constitucional de España, 1780-1812, Madrid 2000.

3 »Derecho natural y de gentes, tratados y relaciones diplomáticas de España (doctorado, 1842); „Filosofía del derecho; derecho internacional público y privado« (doctorado, 1852); »Historia de las relaciones políticas, diplomáticas y comerciales de España con las demás Potencias« (1857);
»Derecho internacional, común y particular de España« (doctorado, 1857); »Historia de las relaciones políticas, diplomáticas y comerciales de España con las demás naciones« (1866); »Derecho internacional, público y privado« (doctorado, 1866); »Derecho internacional « (doctorado, 1868); »Historia y examen crítico de los principales tratados de España con otras potencias« (doctorado, 1868, 1880); "Derecho internacional público« (1883); »Derecho internacional privado« (1883); »Historia del Derecho internacional «(doctorado, 1900).

4 Valga el caso de Camilo Barcia Trelles, en 171 y otra vez en 203; los ejemplos pueden multiplicarse. 
dudar que Rasilla comete demasiadas faltas de respeto a sus lectores. Las errata son inexcusables por numerosas. ${ }^{5}$ Las relaciones cronológica (xiixvi) y bibliográfica (309-350) resultan muy deficientes: con fechas irrelevantes o carentes de ilustración, ${ }^{\mathbf{6}}$ con efemérides equívocas, ${ }^{7}$ con obras citadas varias veces o de forma equivocada, o presen- tes en las notas mas ausentes en la relación final. Y por último: en un libro que contiene tanta información - argumentos, fechas, nombres, títulos - no tiene perdón el índice improvisado que lo remata $(351-353)$.

\section{Mariana Dias Paes}

\section{Novas perspectivas para uma História Atlântica do Direito*}

Já há muitos anos, as análises dos historiadores do direito vêm sendo influenciadas pelas atuais configurações dos Estados nacionais. A produção de normas e categorias jurídicas, no entanto, é melhor entendida, historicamente, se levarmos em consideração outros espaços, não limitados às configurações territoriais contemporâneas. Nesse sentido, têm-se desenvolvido, recentemente, pesquisas que procuram expandir as perspectivas da História do Direito, adotando pressupostos teórico-metodológicos relacionados aos debates da História Global e das Histórias Conectadas. Para o caso brasileiro, a perspectiva da História Atlântica se mostra bastante frutífera para pensarmos a produção de normatividades no ambiente jurídico compartilhado do Atlântico. Para isso, é essencial que os historiadores do direito tenham contato com a literatura sobre a África. Assim como as sociedades estabelecidas na Europa e na América, aquelas que estavam na África participaram, intensamente, desse processo compartilhado de produção normativa. Com o objetivo de apresentar, à comunidade acadêmica lusófona, os mais recentes desenvolvimentos da historiografia sobre a África CentroOcidental, esta resenha trata de três livros que levantam importantes questões para pensarmos o
5 Así, es demasiado frecuente el uso de minúsculas en las citas de título en lengua alemana $(v . g r .119$, n. 143 , por nada decir del uso repetido de Volkgeist), pero la bárbara práctica se ha llevado también a nombres y palabras en otros idiomas (266, n. 223; 293, n. 136). Peor es el error en las fechas (96, Cristopher C. Langdell; 127, Field Code) y la confusión entre personajes (126, consideraciones sobre el profesor Rafael de Ureña y Smenjaud referidas a su hijo, el diplomático Rafael de Ureña y Sanz) o los nombres equivocados $(50,71$, $74,121,124,215,298$, entre otras ... incluso en la relación bibliográfica: García Moreno aparece siempre como García Montero). Los signos de puntuación también presentan una deriva errática. ¿Será que Brill-Nijhoff, responsables materiales de la publicación, carecen de correctores?

6 »1900«, a secas, en xiv. ¿Se trata del Tratado de París que delimitó la exigua presencia española en el Golfo de Guinea, suicidio del delegado español incluido? Por lo demás, parece irrelevante recordar (xiii) que Christopher C. Langdell accedió al decanato de la Harvard Law School en 1870.

7 »1938. Fundamental Laws of the Realm (1938-1978)«, leemos en xvi. La fecha corresponde a la promulgación del Fuero del Trabajo, primera de una serie de "leyes fundamentales« que no pueden sin más subsumirse en tal Fuero, de estilo y contenido nazifascista.

\footnotetext{
Mariana Pinho Candido, Fronteiras da escravidão: escravatura, comércio e identidade em Benguela (17801850), Benguela: Ondjiri 2018, 282 p., ISBN 978-989-99622-0-4 Cristina Nogueira da Silva, A construção jurídica dos territórios ultramarinos portugueses no século XIX: modelos, doutrinas e leis, Lisboa: Imprensa de Ciências Sociais 2017, 159 p., ISBN 978-972-671-399-9 Flávia Maria de Carvalho, Sobas e os homens do rei: relações de poder e escravidão em Angola (séculos XVII e XVIII), Maceió: Edufal 2015, 329 p., ISBN 978-85-7177-893-1
} 